\title{
How old are you, and how many of these have you done? Fielding questions of age and experience in your early career

\author{
Seth Krantz, MD, a,b and HelenMari Merritt-Genore, DO
}

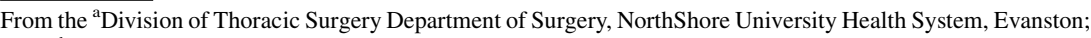
the ${ }^{\mathrm{b}}$ Department of Surgery, University of Chicago Pritzker School of Medicine, Chicago, Ill; and the ${ }^{\mathrm{c}}$ Division of Cardiothoracic Surgery, Department of Surgery University of Nebraska Medical Center, Omaha, Neb. Disclosures: Authors have nothing to disclose with regard to commercial support.

Received for publication Jan 1, 2017; revisions received March 22, 2017; accepted for publication April 12, 2017; available ahead of print May 26, 2017.

Address for reprints: HelenMari Merritt-Genore, DO, University of Nebraska Medical Center, 982315 Nebraska Medical Center, Omaha, NE 98198-2315 (E-mail: h.merrittgenore@unmc.edu).

J Thorac Cardiovasc Surg 2017;154:565-7

$0022-5223 / \$ 36.00$

Copyright (C) 2017 by The American Association for Thoracic Surgery

http://dx.doi.org/10.1016/j.jtcvs.2017.04.022
}

"Oh, so you're our new surgeon. You look just like my granddaughter. Did you just graduate high school?" says the friendly preoperative nurse starting an intravenous line. Dr Merritt-Genore had been on the faculty for about a month but had not yet been become acquainted with this nurse. The patient's daughter was also a nurse, and it had taken hours during the past week to establish rapport with his family. The interaction did not exactly inspire confidence in the moments before surgery. The transition from residency, where young faces are expected, into independent practice may be rocky for a variety of reasons, not the least of which is overcoming patient expectations of what a cardiothoracic surgeon "should" look like. This occurrence is not unique to cardiothoracic surgery, or even to medicine. A recent study, "A Corporate Beauty Contest," ${ }^{1}$ demonstrated that chief executive officers with more "mature" faces have more career success and greater monetary compensation than do those with "baby" faces. Interestingly, this same study found no evidence that a mature face is actually associated with superior performance. With the completion of cardiothoracic surgery training requiring an average of 8.7 years of residency and fellowship beyond medical school, ${ }^{2}$ budding cardiothoracic surgeons arrive on the job market in their mid to late 30s for their first "real job." In contrast, American Medical Association data suggest that cardiothoracic surgeons are operating well into their 60 s and 70 s and estimates that more than $50 \%$ of active cardiothoracic surgeons are older than 55 years, with more than $15 \%$ between 65 and 74 years old. ${ }^{3}$ In other words, there is a stark contrast in public perception between what a surgeon "should" look like and the surgeon whom the patient might meet on the day of consultation. As early-career cardiothoracic surgeons, today we explore how to field early-career questions of age and experience.

\section{KNOW YOUR CASE VOLUMES}

Although the questions of age and experience often go arm in arm, they are actually not asking the same thing.

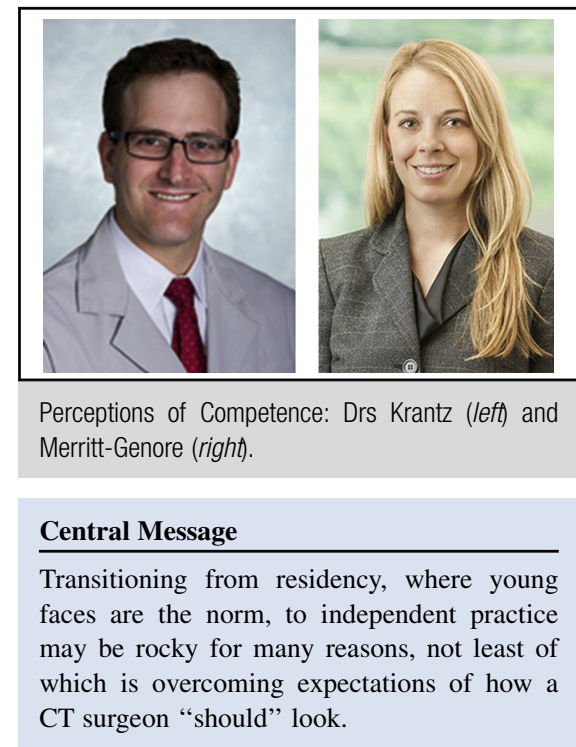

See Editorial Commentary page 568.

As a young surgeon, it is important to differentiate between your age and your case volumes, especially annual case volume as opposed to cumulative case volume. A 2006 study from the University of Michigan determined that for many procedures, surgeon age is not an important predictor of the operative mortality. ${ }^{4}$ Patient outcomes in 8 procedures (including aortic valve replacement and coronary artery bypass grafting) were analyzed with respect to surgeon age and operative mortality. Surgeons older than 60 years, particularly those with low procedure volumes, were actually associated with a higher operative mortality than were their younger counterparts. One of the study's authors concluded that patients should ask how many procedures a surgeon does a year, rather than focus on the doctor's gray hair.

There is a bit of controversy involved in the standard informed consent. Are surgeons required to disclose when the surgery is going to be the first ever performed independently by the surgeon? Legally, no. But should we be? It is a complex topic. Even in training, many surgical residents do not directly address how much of case they will be performing, with or without the attending surgeon in the operating room. ${ }^{5}$ Likewise, a transition period exists after the training wheels of surgery come off, and especially during this time we must seek excellent mentors. As patients become more active consumers and self-advocates, one of the must-ask 
questions is still surgeon experience. It is true that in general, hospital, and surgeon annual case volumes are associated with improved outcomes. ${ }^{6}$ How then is a young attending, especially one in his or her first year, supposed to answer that question? The question is, should you count the cases that you did in training? The answer is yes, but you must do so in a way that is honest and truthful. Surgical training is among the most rigorous and structured of any profession, with required case volumes, graded supervision, and a curriculum of both cognitive and technical skills. If you were the primary surgeon, physically and mentally performing the critical steps of an operation, then it is an operation that you have performed and should be counted as such and described in an honest manner. What most patients really want to know is whether you are well trained to do the procedure. Find a way to address the underlying question specifically. For example, you could say, "I have been here for 2 months now in independent practice. Before that I spent 7 years training with experts in the field. This will be my first solo case of this kind, but I have asked my senior partner to be available in case anything unexpected arises." Admitting that you will ask for assistance for complex situations demonstrates good judgment.

Young surgeons can also take heart that this scenario gets much easier when you have at least 1 year of cases under your belt. After that critical first year, you can say, "Well, last year I did more than 230 cases, 125 of which were coronary bypasses just like what you need." If you have conducted research-either in training or in independent practice-it is reasonable to incorporate relevant studies into the conversation. Be honest when cases are rare, and few surgeons can boast large experiences. In summary, keep your case logs up to date, and commit to memory key case volumes so that you have a number in mind when patients ask.

\section{FIND A COMMON GROUND}

Although it would seem to go without saying, you are not trying to sell anything to your patients. Patients may have hesitations about an operation for a host of reasons apart from you. When patients do have reservations that are related to your age or experience, much discomfort can be allayed with good medical practice. Take the time to listen to each patient's concerns, connect on a personal level, and be an open communicator as well as advocate for the patient. This conduct projects a quiet confidence that will often overcome the "how old are you?" effect.

One effective approach is finding common ground, which shows that you listen, a key factor in instilling trust between patient and surgeon. You may recognize a devotional book on the patient's bedside table, and relate a shared faith. You may have the good luck to share the same name with a patient's wife, and even the same birthday as the patient. Learn one thing about each patient beyond the medical problem.
What does or did he or she do for a living? Where is the patient from originally? What are the patient's hobbies or interests? It does not really take any extra time and frequently comes up during the course of a basic history. Listening to those things and making a personal connection can overcome much of the initial apprehension of looking young. Remember, one of the very best things about being a faculty member is that your time is again your own. You can take time to visit with patients instead of "running the list" in your head during consults. You can remember what initially drove you into medicine-the patients! Explain complications, how likely they are to occur, and what your expectations are for the postoperative course. Ensure that everyone in the room understands.

It is helpful to put yourself in the patient's shoes when it comes to these types of decisions. While still a resident, one of the author's (H.M.G.) own newborn son needed an arterial switch for transposition, and requested the most senior faculty member. Both other partners were excellent surgeons and mentors as well, and undoubtedly either would have performed a technically sound operation. After scrubbing numerous tough cases with the boss, however, the author ultimately felt most comfortable with him at the helm of the ship. Give your patients the same privilege as you yourself would expect (or even demand) for your loved one. For each patient and family, it is personal.

Most of the time, listening empathetically and being forthright will allow patients to become comfortable with and confident in you, and ultimately, they will request that you be their surgeon. If they do not, respect that decision and move on; that too shows maturity and garners respect.

\section{GIVE VALUE TO THE TEAM}

Truly great outcomes depend on your team. Data suggest that hospital volume for complex cases correlates with patient outcomes. ${ }^{7}$ A large part of a successful outcome stems from the "ability to rescue" after a complication occurs. This ability extends beyond the individual surgeon and encompasses the broader system: anesthesiologists, critical care physicians, surgical nurses and scrub techs, critical care and floor nurses, cardiology, interventional radiology, and so on. When talking with a patient about an operation, highlight your team, their experience, and the overall hospital volume. Remember that when you head into the operating room, you are not just taking the patient with you. You are taking the entire team and the resources of the hospital. The team is tethered to you and your decisions, but they are also a life raft for both you and the patient. It is thus not only acceptable but imperative to acknowledge and highlight this team role when counseling a patient. Doing so will pay innumerable dividends: not only will you instill confidence in you and the institution, you will validate and publicly support the people on whom you rely. 


\section{CONCLUSIONS}

In the end, there is really only one thing to remember: the patient always comes first. If there are any doubts about your own ability to provide the best operation and postoperative care, both personally and institutionally, make sure that patient gets the right care. Know your case volumes and their limits. Value your training, but do not overinflate your experiences. Communicate effectively. Praise your team's strengths, and keep your focus on the patient.

\section{References}

1. Graham J, Harvey C, Puri M. A corporate beauty contest. National Bureau of Economic Research Working Paper No. 15906. April 2010. Available at: http://www. nber.org/papers/w15906.
2. Ikonomidis J. The Society of Thoracic Surgeons Thoracic Surgery Practice and Access Task Force: 2014 workforce report. Ann Thorac Surg. 2016; $102: 2118-25$.

3. Grover A, Gorman K, Dall TM, Jonas R, Lytle B, Shemin R, et al Shortage of cardiothoracic surgeons is likely by 2020. Circulation. 2009; 120:488-94.

4. Waljee JF, Greenfield LJ, Dimick JB, Birkmeyer JD. Surgeon age and operative mortality in the United States. Ann Surg. 2006;244:353-62.

5. Guwande A. Complications: a surgeon's notes on an imperfect science. New York: Metropolitan Books; 2002.

6. Birkmeyer JD, Stukel TA, Siewers AE, Goodney PP, Wennberg DE, Lucas FL. Surgeon volume and operative mortality in the United States. $N$ Engl J Med. 2003:349:2117-27.

7. Markar SR, Karthikesalingam A, Thrumurthy S, Low DE. Volumeoutcome relationship in surgery for esophageal malignancy: systematic review and meta-analysis 2000-2011. J Gastrointest Surg. 2012;16: 1055-63. 